\title{
The Park Creation Boom in Switzerland
}

\author{
Andreas Weissen
}

\section{Abstract}

In 1914, the Swiss National Park was created in Grisons as only the second of its kind in Europe. For nearly a century after this pioneering act, nothing much happened in Switzerland. In recent years, however, Switzerland has experienced a veritable park creation boom. In the last two years alone, eighteen proposals for creating new parks were put to the federal authorities. About a dozen additional projects are currently in preparation.

\section{Park categories}

By international standards, the Swiss National Park is not a park but a strict nature reserve (IUCN category I). Human activity is confined to monitoring natural processes and to using only the designated paths.

The new parks currently being proposed in Switzerland are orientated on IUCN category II for national parks and nature discovery parks, and on category $\mathrm{V}$ for regional nature parks. At the end of 2007, the revised Nature and Cultural Heritage Protection Act NHG came into force. It forms the legal basis for the creation and operation of "parks of national importance" and distinguishes three categories of parks:

- National Parks: in their core zones, these offer undisturbed habitats for the indigenous flora and fauna as well as for the dynamic development of the natural landscape itself. In the transition zones around the national parks, the cultural landscape is used sustainably in a near-natural manner.

- Regional Nature Parks: these are partly inhabited rural areas with highly valuable natural and landscape characteristics. Buildings and installations are well integrated into the landscape and the respective villages. Regional nature parks serve to maintain the quality of natural resources and the landscape and to enhance a sustainable economy.

- Nature Discovery Parks: these are created near densely populated areas. In their core zones they offer undisturbed habitats for the indigenous flora and fauna to develop dynamically. In the transition zones, which also serve as buffers against detrimental impacts, visitors can discover nature in a variety of ways.

\section{Referenda on each park}

It is the immediately affected population who decides whether a region should become a park and what category of park. In smaller communities, this is usually done in a municipal assembly in which the entire electorate is invited to participate. In larger municipalities, local parliaments decide. This typically Swiss element of direct democracy forces the initiators of parks to inform the population from the very beginning and to integrate all relevant interest groups. The programs

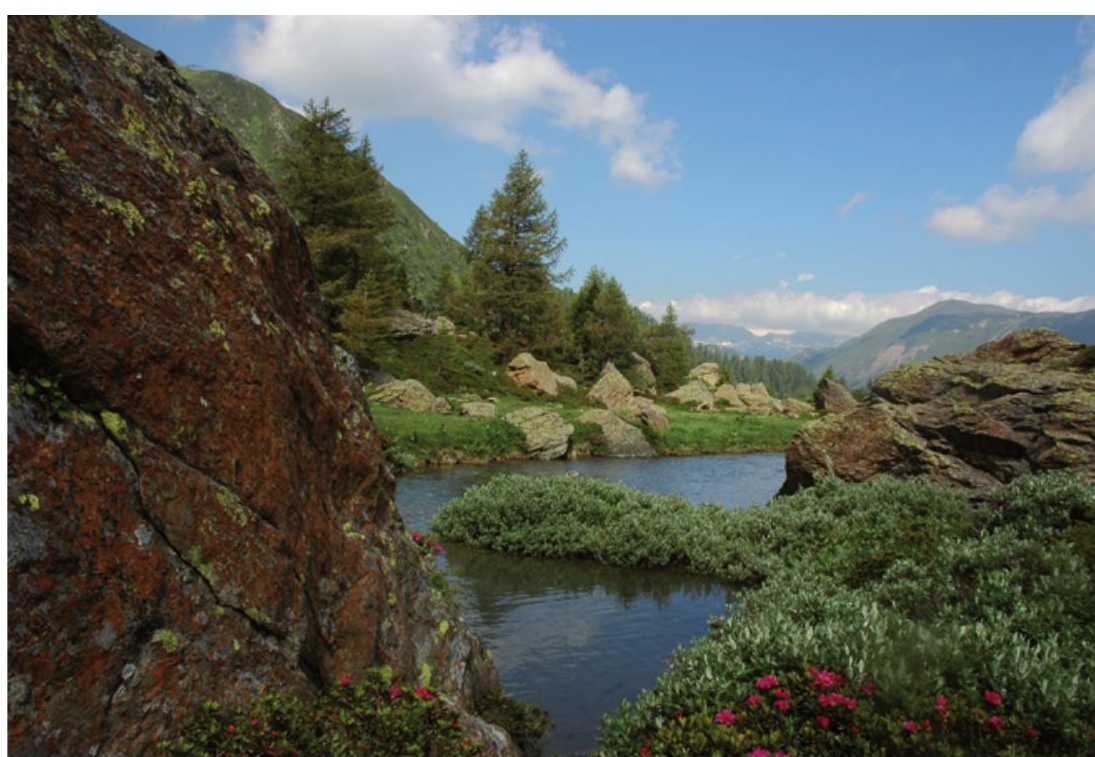

Landschaftspark Binntal (C) Andreas Weissen

for the park ("Management Plan" for its creation and "Charta" for its operation) must be developed in a participatory process. This is why Swiss park projects enjoy wide acceptance from early on.

As operation is only granted for ten years at a time, the population has another say, shortly before the period expires, on whether the project should continue or not. This extended "uncertainty about the continued existence of the park" is a reminder for the park administration to involve the local population in the ongoing development of the park during operation. There is, however, a flip side to this democratic process. Parks are created where the local population wants them. The map of Swiss parks thus reflects first and foremost the political acceptance of the park projects. There is no representative distribution across the different biogeographical regions of the country. Moreover, the category of regional nature park, which combines protection and use along the principles of sustainability, is overrepresented vis-à-vis the other two categories. The federal authorities cannot control developments here but are bound by the will of the people. On top of proving that it is politically accepted, each project must fulfil two further conditions to be accepted as a "Park of National Importance". The area must include natural, scenic or settlement characteristics of 


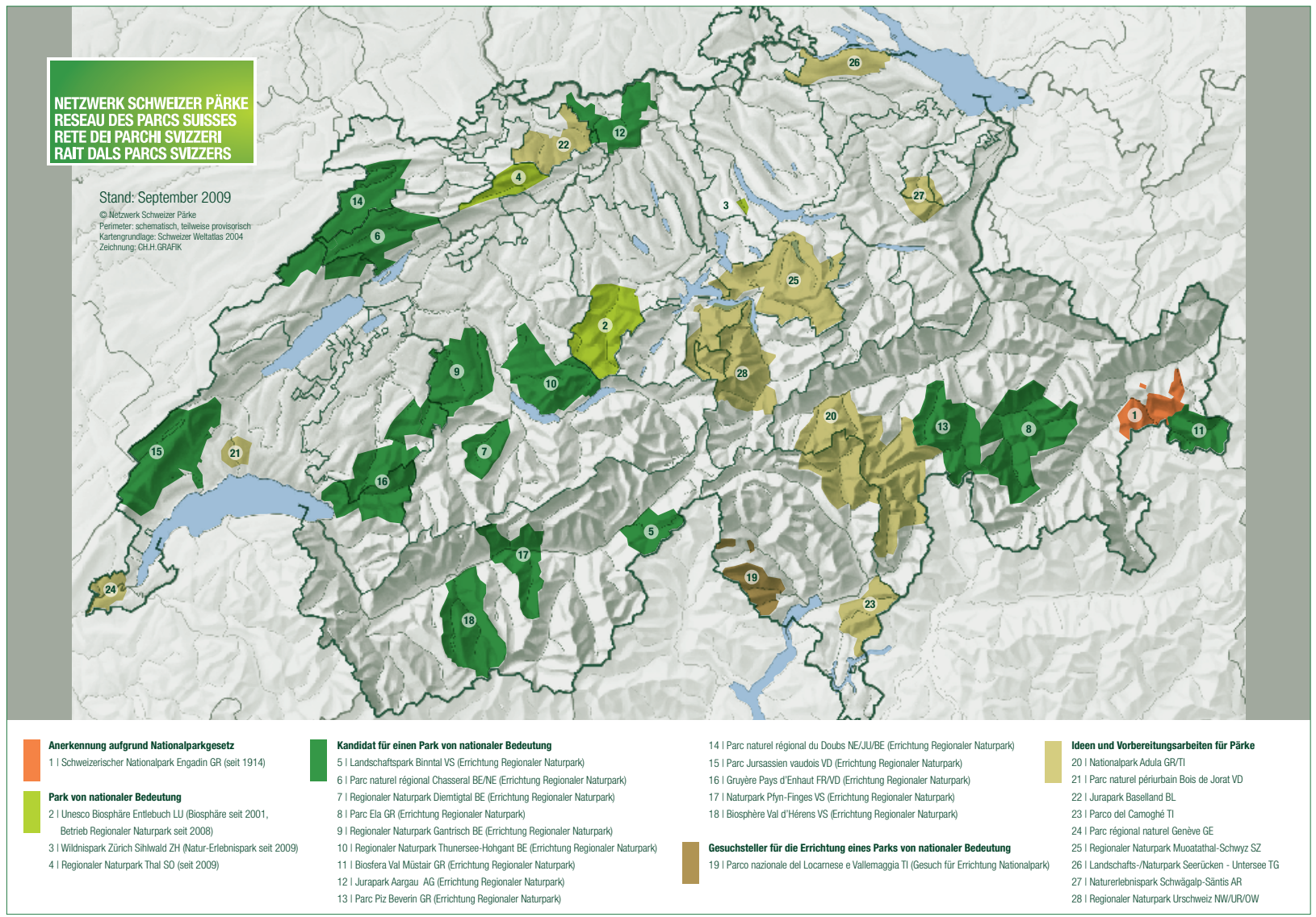

great value and be of a sufficiently large size. In addition, each park must present a convincing programme for the establishment phase and another one for the first ten-year period of operation. The federal authorities review both. If they approve the programs, the path is clear towards a park designation.

\section{Dynamic Swiss park situation}

Last year, the first project was awarded the label "Park of National Importance". It is the UNESCO Biosphere Reserve Entlebuch in the canton Luzern, which received its international designation in 2001. Under national law, the biosphere reserve is the equivalent of a regional nature park. In autumn 2009, Thal in the Solothurn Jura was designated as a nature park and the Zurich Wilderness Park (Wildnispark Zürich), with the natural forest reserve Sihlwald, was recognized as nature discovery park. This category of park is meant to be established near agglomerations and must have a core zone of at least $4 \mathrm{~km}^{2}$ plus an additional buffer zone.

Another fourteen park projects have reached the status of a candidate. This means that they have passed the first hurdle of approval by the federal authorities and are now required to produce a Charta for the first ten-year period of operation. In addition, about a dozen projects are currently busy producing feasibility studies or management plans.

The seventeen new parks and candidates cover a surface of $5750 \mathrm{~km}^{2}$, that is $14 \%$ of the total territory of Switzerland. Eleven cantons and 268 municipalities are involved.

The Swiss park situation is in flux. Hardly a month goes by without a new project being launched somewhere. Several projects, however, have disappeared again due to a lack of acceptance, e.g. the Muveran National Park on a bend in the Rhone, between the cantons of Wallis and Waadt, or the Maderanertal project in canton Uri and the Toggenburg project in canton St. Gallen. To make matters worse, a municipality will abandon support for a park after a negative referendum and others follow suit. The total picture of Swiss parks is only slowly emerging.

\section{Networking between parks and projects}

About two years ago, some two dozen parks and park projects established a special umbrella organization, the Swiss Parks Network (Netzwerk Schweizer Pärke). The network organizes information sharing among parks, represents their interests vis-à-vis national partners and takes on joint PR tasks. On 1 February 2009, the network established its own office in Bern.

\section{Author}

\section{Andreas Weissen}

Director of the Network of Swiss Parks, former president of CIPRA International, worked on the WWF Alpine Programme, degrees in communication, education and economic history. 